\title{
Chios Hospital Information System Assessment
}

\author{
Konstantinos KARITIS ${ }^{1}$, Parisis GALLOS, Ioannis S. TRIANTAFYLLOU \\ and Vassilis PLAGIANAKOS \\ Department of Computer Science and Biomedical Informatics, \\ University of Thessaly, Lamia, Greece
}

\begin{abstract}
A very important aspect for organizations that provide healthcare services is to have fully functional and successful information systems. A successful hospital information system can contribute to high quality healthcare services provided to the patients of the hospital. In this paper, is presented the evaluation of the information system of Chios Hospital, "Skylitsio". The survey was conducted using a questionnaire which consists demographic questions and questions that measure the factors of the DeLone \& McLean success model. The participants of the survey were 71 users of the clinical information system. Cronbach's alpha reliability test, descriptive statistics, and further data analyses to investigate the relations between the factors of the DeLone \& McLean success model were performed. Based on the results, the users of the information system are satisfied with it, as well as they find the system useful and easy to use. The average value of the "information quality" is 3.78 out of 5 , the "system quality" is 3.61 , the "service quality" is 3.45 , the "use" is 3.83 , the "user satisfaction" is 3.46 , and the "user benefit" is 3.76 . The research concludes with a validation of the DeLone \& McLean success model and it seems that the information system of the General Hospital of Chios is successful based on the users' opinions.
\end{abstract}

Keywords. Evaluation, Hospital Information System, Success, DeLone \& McLean, "Skylitsio" Chios General Hospital, Information Quality, System Quality, Use, User Satisfaction, Perceived Benefits

\section{Introduction}

The last few decades, a lot of information and communications technologies were applied in Hospitals and other healthcare organizations to cover administrative and financial needs, as well as to manage patient information [1]. The main goal of these systems was to simplify the communication and documentation through the use of standardized orders as well as, care or treatment plans [2]. A hospital information system (HIS) can manage patients' admissions, medical records, accounting information, several services, nursing, laboratories, radiology, pharmacy, central procurement, dietary services, staff and payroll data. HIS are integrated computer systems designed to facilitate the management of all medical and administrative data of a hospital and also to improve the quality of the provided healthcare services [3]. The Information systems evaluation is an important process [4], especially on healthcare setting, as it can ensure the efficiency and the

${ }^{1}$ Corresponding Author, Konstantinos Karitis, Department of Computer Science and Biomedical Informatics, University of Thessaly, Lamia, Greece; E-mail: konstantinoska98@gmail.com. 
effectiveness of the HIS. According to the international literature, the success of the information systems plays an important role to the organization's performance [5]. The success of an information system can be measured by three levels, the Organizational level, the Process success level, and the Individual level where the satisfaction from the system usage and the perceived usefulness by the users are examined [5].

Information systems success model (IS success model) was created by DeLone and McLean in 1992 [6] and it is one of the most well-known evaluation models. The model includes the "System Quality" factor which describes how "good" the information system is in terms of its functional characteristics. The "Information Quality" defines how "good" the information system is in terms of its outputs. The "Service quality" describes how "good" the information system is in terms of its available services. The "System Use" refers to the use and utilization of outputs by the information system itself. The "User Satisfaction" measures how satisfied the users are as they use the system and is considered as an important parameter for measuring the success of an information system. The System "Benefits" refers to the benefits that system can offer and is an important aspect of the overall value of the system to its users or organization [7]. The IS success model has been broadly used for information systems assessment in several domains and in healthcare domain too [8-11].

The purpose of this research is to examine the success of the clinical information system of "Skylitsio" General Hospital of Chios using the DeLone and McLean success model.

\section{Methods}

A paper-based questionnaire was used as a research tool that was distributed among the users of Chios Hospital Information System in June 2020 after a relevant approval of the Hospital's scientific committee. "Skylitsio" General Hospital of Chios is located in the northeastern Aegean Island of Chios, in Greece. The questionnaire aimed to record the opinions of the users of the clinical information subsystem of the hospital. The questionnaire was created based on the DeLone \& McLean information systems success model [6-7] and was divided into two parts. The first part included four demographic questions (about age, gender, specialty of the user, computer systems familiarity) while the second part included twenty-two questions to assess six factors of the DeLone \& McLean evaluation model [7]. The questions were based on other surveys using the DeLone \& McLean evaluation model and were translated in Greek language [8-14]. The factors that where examined were "information quality", "system quality", "service quality", "system usage" ("use"), "user satisfaction", "perceived benefits from using the system" ("benefits"). The aforementioned factors were measured by a five-point Likert scale. The Linkert five-point scale consists of five predefined answers that correspond to a specific numerical value from one to five and express the degree of agreement or disagreement with a particular statement [15]. The data analyses have been performed using SPSS version 25 software. More specifically, the questionnaire's reliability was examined by applying Cronbach's alpha test, as well as new variables were created to investigate the relations between the factors. Descriptive statistics of all the variables of the questionnaire were calculated and correlation analyses between the factors was conducted. To examine the relations between the factors, Spearman correlation coefficients were calculated. Finally, Linear regression analysis was used to evaluate the research model. 


\section{Results}

71 users of the Chios Hospital Information system participated in this survey. From the 71 users, $25(35.2 \%)$ are men and $46(64.8 \%)$ are women. The mean age of the study participants was 42.03, $35(49.3 \%)$ belong to the administrative staff, 21 (29.6\%) belong to the Nursing staff, $12(16.9 \%)$ belong to the medical staff and $3(4.2 \%)$ belong to the rest of the hospital staff. The users who consider that they have high familiarity with computers and ICT (Information and Communication Technologies) were 38 (53.5\%), those who consider that they have average familiarity with computers and ICT were 31 $(43.7 \%)$ and $2(2.8 \%)$ consider that they have low familiarity with computers and ICT. The internal consistency of the questionnaire items is reflected in Cronbach's Alpha coefficient which is 0.936 . Table 1 presents the average of each dimension, the Cronbach's Alpha scores and the spearman correlation results. All the results found be statistically significant with $p$-value $<0.01$. Multiple linear regression was performed to investigate (a) how "system quality" and "information quality" are associated with "use", (b) how "system quality" and "information quality" are associated with "user satisfaction" and (c) how "use" and "user satisfaction" are associated with "benefits". The linear regression equation for (a) is "use" $=0.538+(0.328 *$ "system quality") + $(0.577 *$ "info quality") with p-value $<0.01$ and $\mathrm{R} 2=0.371$. For (b) the linear regression equation is "user satisfaction" $=-0.374+(0.518 *$ "system quality" $)+(0.521 *$ "info quality") with $p$-value $<0.01$ and $\mathrm{R} 2=0.675$. Finally, the linear regression equation for (c) is "system benefits" $=1.46+(0.401 *$ "use" $)+(0.222 *$ "user satisfaction") with $\mathrm{R} 2=$ 0.605 and $p$-value $<0.01$.

Table 1. Table 1 presents the average of each dimension, the Cronbach's Alpha scores and the spearman correlation results.

\begin{tabular}{|c|c|c|c|c|c|}
\hline Dimensions & $\begin{array}{c}\text { Average } \\
\text { Value } \\
(\max =5)\end{array}$ & $\begin{array}{l}\text { Cronbach's } \\
\text { Alpha } \\
\text { Coefficient }\end{array}$ & $\begin{array}{l}\text { Associated } \\
\text { Dimension }\end{array}$ & $\begin{array}{c}\text { Spearman } \\
\text { Correlation } \\
\text { Coefficient }\end{array}$ & p-value \\
\hline \multirow{2}{*}{$\begin{array}{l}\text { Information } \\
\text { Quality }\end{array}$} & \multirow[t]{2}{*}{3.78} & \multirow[t]{2}{*}{0.810} & Use & 0.497 & $<0.01$ \\
\hline & & & User Satisfaction & 0.511 & $<0.01$ \\
\hline \multirow{2}{*}{ System Quality } & \multirow[t]{2}{*}{3.61} & \multirow[t]{2}{*}{0.758} & Use & 0.424 & $<0.01$ \\
\hline & & & User Satisfaction & 0.487 & $<0.01$ \\
\hline \multirow[t]{2}{*}{ Use } & \multirow[t]{2}{*}{3.83} & \multirow[t]{2}{*}{0.891} & User Satisfaction & 0.714 & $<0.01$ \\
\hline & & & Benefits & 0.467 & $<0.01$ \\
\hline User Satisfaction & 3.46 & 0.913 & Benefits & 0.411 & $<0.01$ \\
\hline \multirow{2}{*}{ Benefits } & \multirow[t]{2}{*}{3.76} & \multirow[t]{2}{*}{0.878} & User Satisfaction & 0.411 & $<0.01$ \\
\hline & & & Use & 0.467 & $<0.01$ \\
\hline Service Quality & 3.45 & 0.767 & & & \\
\hline
\end{tabular}

\section{Discussion}

The average value for all the variables and the model factors is above the median $(2.5$ out of 5), so it can be assumed that the users have a positive opinion about the information system quality, data quality, and services quality. The system usage, the user satisfaction and the perceived benefits of the system usage are also above the median and can be assumed as positive results. Most users consider the information system to have high "information quality", high "system quality" and high "service quality". In particular, they believe that the information receiving by the system is correct, useful, accurate and 
reliable, they also consider the information system to be easy to use, flexible and easily learnable. Users also consider that they can rely on an information system to get the information they need. They also believe that there is adequate infrastructure and technical support for the system. Users also find the information system useful as it improves the performance of their work, facilitates their work and helps them complete their tasks faster. They also believe that they benefit from using the system as the information system facilitates access to patient information, improves patient care, helps make better decisions and helps to create a paperless environment, only through electronic means. According to the aforementioned results, it seems that the quality of the system affects the users' satisfaction. The better they consider the system to be, the more satisfied they are with it. It also seems that the quality of information affects the use of the system by the Hospital staff. The higher the quality of the information is, the more users use the system. In addition, it seems that the quality of information also affects the satisfaction of the use of the system. The higher the quality they consider the information produced by the system, the more satisfied they are with its use. Furthermore, it seems that the use of the system affects the satisfaction felt by the staff of the Hospital. The more they use the system the more satisfied they feel with it. Supplementary, it seems that the use of the system affects the benefit felt by the staff of the Hospital. The more they use the system the more they feel they receive benefits from it, also it seems that the satisfaction from the use of the system affects the benefit that the staff of the Hospital considers having from its usage. The more satisfied they are with the use of the system, the more they feel they benefit from it.

This research also found that the value of the variable of the factor "use" is affected by changes in the value of the factor "system quality" but even more than the changes of the value of the factor "information quality", also the value of the variable of the factor "user satisfaction" is affected by changes in the value of the factor "information quality" but even more than the changes in the value of the factor "system quality" and the value of the variable factor "benefits from the use of the system" is affected by changes in the value of the factor "use" but not from changes in the value of the "user satisfaction" factor. Based on the above, it can be concluded that there are statistically significant relations between some of the factors of the DeLone \& McLean IS success model. Other previous related studies $[8-10 ; 16-20]$ have been produced similar results regarding the success of Hospital Information Systems and other Healthcare Information Systems around the globe.

\section{Conclusions}

Evaluating the success of an information system is an important and necessary process because through the assessment shortcomings and errors of the system can be identified. Thus, the system evaluation contributes to the system's smooth operation and to the quality of the provided health services. In the present study, the success of the clinical information system of Chios General Hospital "Skylitsio" was investigated using the DeLone \& McLean model. According the aforementioned positive, it seems that the information system of Chios Hospital is successful based on the opinions of its users. The research had some limitations, like the large workload of the staff of the Hospital but also the high Covid-19 cases in the island of Chios during the research period that made the data collection very difficult and the sample size quite small. Future work includes a proposal for system upgrade based on evaluation results and needs assessment 
and the evaluation of other subsystems of the Hospital Information System based on more users' opinions.

\section{Acknowledgements}

Authors would like to thank the staff and the scientific committee of "Skylitsio" Chios General Hospital for their cooperation.

\section{References}

[1] Hammond WE. Hospital information systems: a review in perspective. Yearbook of medical informatics. 1994; 3.01: 95-102.

[2] Ozbolt G, Bakken S. 'Patient care systems', In: Shortliffe, E. and Perreault, L. (ed.), Medical Informatics: Computer Applications in Health Care and Biomedicine, 2nd ed., New York: Springer. 2001;421-422.

[3] Venot, A, Burgun A and Quantin C. Medical Informatics, e-Health, Verlag France: Springer. 2014.

[4] Hirschheim R, Smithson S. 'Evaluation of information systems: A critical assessment'. In Willcocks P. and Lester S. (ed.), Beyond the IT Productivity Paradox, (pp. last chapter), Chichester, UK: John Wiley \& Sons. 1999.

[5] Garrity E, Sanders L. Information-systems-success-measurement, Pennsylvania: IGI Global. 1998.

[6] DeLone WH, McLean ER. Information systems success: the quest for the dependent variable. Journal of Information Systems Research. 1992; 3.1:60-95.

[7] DeLone WH and McLean ER. The DeLone and McLean Model of Information Systems Success: A TenYear Update. Journal of Management Information Systems. 2003;19.4:9-30.

[8] Ojo AI. Validation of the delone and mclean information systems success model. Healthc Inform Res. 2017;23(1):60-6.

[9] Ebnehoseini Z, Tabesh H, Deldar K, Mostafavi SM, Tara M. Determining the Hospital Information System (HIS) Success Rate: Development of a New Instrument and Case Study. Open Access Maced J Med Sci. 2019 May 14;7(9):1407-1414.

[10] Arana L, Medina L, Pol E, Tun N. Measuring the Success of Hospital Information System (HIS) at La Loma Luz Adventist Hospital. Available from: https://ojs.ub.edu.bz/index.php/PRNDC/article/view/261/105

[11] Thanos L, Gallos P, Zoulias E, Mantas J. Investigating the Success of "Asklepieio Voulas" Hospital Information System. Stud Health Technol Inform. 2021 May 27;281:620-624.

[12] Gallos P, Minou J, Routsis F, Mantas J. Investigating the Perceived Innovation of the Big Data Technology in Healthcare. Stud Health Technol Inform. 2017;238:151-153.

[13] Gallos P, Daskalakis S, Katharaki M, Liaskos J, Mantas J. How do nursing students perceive the notion of EHR? an empirical investigation. Stud Health Technol Inform. 2011;169:243-7.

[14] Stylianides A, Mantas J, Roupa Z, Yamasaki EN. Development of an Evaluation Framework for Health Information Systems (DIPSA). Acta Inform Med. 2018;26(4):230-234.

[15] IS Research Wiki (2019). Semantic theory of survey response. Obtained through the Internet: https://is.theorizeit.org/wiki/Semantic_theory_of_survey_response, [accessed 8/5/2020].

[16] Alipour J, Karimi A, Ebrahimi S, Ansari F, Mehdipour Y. Success or failure of hospital information systems of public hospitals affiliated with Zahedan University of Medical Sciences: A cross sectional study in the Southeast of Iran. Int J Med Inform 2017;108(August):49-54.

[17] Elsadig M, Nassar DA, Menzli LJ. Healthcare Information System Assessment Case Study Riyadh's Hospitals-KSA. In: First International Conference on Computing, ICC 2019 Proceedings, Part II [Internet]. 2019; 252-62.

[18] Saghaeiannejad-Isfahani S, Saeedbakhsh S, Jahanbakhsh M, Habibi M. Analysis of the quality of hospital information systems in Isfahan teaching hospitals based on the DeLone and McLean model. J Educ Health Promot. 2015;4(February):5.

[19] Cho KW, Bae SK, Ryu JH, Kim KN, An CH, Chae YM. Performance evaluation of public hospital information systems by the information system success model. Healthc Inform Res. 2015;21(1):43-8

[20] Mamma E. Evaluation and Quality of Information Systems in Institutional Organizations. 17th Hell ConfAcabemicLibr [Internet]. 2008; p. 1-14. Ibrahim R, Auliaputra B, Yusoff RCM, Maarop N, Zainuddin NMM, Bahari R. Measuring the Success of Healthcare Information System in Malaysia: A Case Study. IOSR J Bus Manag. 2016;18(4):100-6. 